\title{
The Results of the Campaign for Evaluating Sphygmomanometers Accuracy and their Physical Conditions
}

\author{
Décio Mion Jr, A ngela M. G. Pierin, Débora Cristina Alavarce, José Henrique da Cunha Vasconcellos
}

São Paulo, SP - Brazil

\begin{abstract}
Objective - To evaluate the sphygmomanometers calibration accuracy and the physical conditions of the cuff-bladder, bulb, pump, and valve.
\end{abstract}

Methods - Sixty hundred and forty five aneroid sphygmomanometers were evaluated, 521 used in private practice and 124 used in hospitals. Aneroid manometers were tested against a properly calibrated mercury manometer and were considered calibrated when the error was $\leq 3 \mathrm{~mm} \mathrm{Hg}$. The physical conditions of the cuffs-bladder, bulb, pump, and valve were also evaluated.

Results - Of the aneroid sphygmomanometers tested, $51 \%$ of those used in private practice and $56 \%$ of those used in hospitals were found to be not accurately calibrated. Of these, the magnitude of inaccuracy ranged from 4 to $8 \mathrm{~mm}$ $\mathrm{Hg}$ in $70 \%$ and $51 \%$ of the devices, respectively. The problems found in the cuffs - bladders, bulbs, pumps, and valves of the private practice and hospital devices were bladder damage (34\% vs. $21 \%$, respectively), holes/leaks in the bulbs (22\% vs. $4 \%$, respectively), and rubber aging ( $15 \%$ vs. $12 \%$, respectively). Of the devices tested, $72 \%$ revealed at least one problem interfering with blood pressure measurement accuracy.

Conclusion - Most of the manometers evaluated, whether used in private practice or in hospitals, were found to be inaccurate and unreliable, and their use may jeopardize the diagnosis and treatment of arterial hypertension.

Key words: blood pressure measurement; sphygmomanometers, calibration accuracy

Faculdade de Medicina e Escola de Enfermagem da Universidade de São Paulo. Mailing address: Angela M. G. Pierin - Av. Dr. Enéas de Carvalho Aguiar, 419 05403-000 - São Paulo, SP - Brazil.

Received on $1 / 13 / 99$

Accepted on 5/12/99
Indirect blood pressure measurement using sphygmomanometers and the auscultatory method is a routine procedure in the diagnosis of hypertension. Therefore the accuracy of the values obtained is essential, since errors may deprive hypertensive patients of the benefits of hypertension treatment and expose normotensive patients to unnecessary treatment ${ }^{1-5}$.

Although several factors are important for accurate blood pressure measurement, the most crucial factor to obtain accurate values is to use adequately calibrated devices. Problems related to the calibration of the manometer as well as damage of the bladder, rubber bulbs, pump and valve of the system which allow the inflation and deflation of the cuff can lead to errors in the readings obtained, thus jeopardizing the accuracy of the measurement.

In Brazil, as in most countries, little is known about the calibration accuracy of devices used for indirect blood pressure measurement, whether such devices are used in private practice or hospitals. It occurs especially because health-care professionals are not used to checking the calibration of such devices. Therefore, we decided to investigate this problem in order to contribute to increase health-care professionals awareness of the importance of calibration by the Campaign for Checking the Calibration of Blood Pressure measuring Devices conducted by the Hypertension League of the General Hospital, Nephrology Discipline of the Medical School, University of São Paulo in Brazilian congresses from 1995 to 1997.

\section{Methods}

Six hundred and forty five aneroid sphygmomanometers were evaluated and divided in two groups: 1) private practice aneroid sphygmomanometers $(n=521)$, which belonged to Brazilian doctors, consisting of 474 aneroid sphygmomanometers that were evaluated in the Campaign for Checking the Calibration of Blood Pressure Measuring Devices and 47 in private offices located in the central area of the City of São Paulo where there are many of doctors who received a letter asking for consent to evaluate 
their blood pressure measuring devices; and 2) hospital aneroid sphygmomanometers $(n=124)$ from two public hospitals in the city of São Paulo. The Campaign for Checking the Calibration of Blood Pressure Measuring Devices was conducted by the Hypertension League of the General Hospital, Nephrology Discipline of the Medical School, University of São Paulo in Brazilian congresses from 1995 to 1997 , and was sponsored by the Brazilian Cardiology Society, Brazilian Hypertension Society, Brazilian Nephrology Society, Cardiology Society of the State of São Paulo and Hypertension League of the State of Bahia and was encouraged by the National Institute of Metrology. The doctors, who attended these events, received a letter before the event, inviting them to take their sphygmomanometers to the event so that they could be evaluated. The evaluation of the devices was performed in the following events: $16^{\text {th }}$ Congress of the Cardiology Society of the State of São Paulo, Cardiology Society of the State of São Paulo, held in Campinas, SP, $1995 ; 4^{\text {th }}$ Congress of the Brazilian Hypertension Society, Brazilian Hypertension Society, held in Recife, PE, 1995; $5^{\text {th }}$ Congress of the Brazilian Hypertension Society and Latin-American Meeting on Hypertension of the Inter-American Hypertension Society, Brazilian Hypertension Society, held in São Paulo, SP, $1996 ; 51^{\text {st }}$ Congress of the Brazilian Cardiology Society, Brazilian Cardiology Society, held in Salvador, BA, 1995; $18^{\text {th }}$ Brazilian Congress of Nephrology, Brazilian Nephrology Society, held in São Paulo, SP, 1996; $18^{\text {th }}$ Congress of the Cardiology Society of the State of São Paulo, Cardiology Society of the State of São Paulo, held in Campos do Jordão, SP, $1997 ; 6^{\text {th }}$ Congress of the Brazilian Hypertension Society, Brazilian Hypertension Society, held in Rio de Janeiro, RJ, 1997; 53 ${ }^{\text {rd }}$ Congress of the Brazilian Cardiology Society, Brazilian Cardiology Society, held in São Paulo, SP, 1997; $1^{\text {st }}$ Annual Symposium of the Hypertension and Arteriosclerosis League of the State of Bahia, held in Salvador, BA, 1996; and $2^{\text {nd }}$ Annual Symposium of the Hypertension and Arteriosclerosis League of the State of Bahia, held in Salvador, BA, 1997.

Of the 645 sphygmomanometers evaluated, 171 (47 from private offices and 124 from hospitals) were exclusively from the City of São Paulo whereas 273 were from events held in the State of São Paulo and the city of Rio de Janeiro. Of the remaining 201 devices, 149 were evaluated in events held in Salvador and 52 in Recife. Thus, $69 \%$ of the devices were evaluated in the southeastern region and $31 \%$ in the northeastern region.

The evaluation tests were conducted by a technician of the Specialized Service Shop for Evaluation and Repair of the University of São Paulo General Hospital, Medical School and by an undergraduate student, studying at the Nursing School of the University of São Paulo. These individuals were properly trained under the supervision of the preceptors of this study.

The data collected were recorded on a special form, furnishing information about the following items: identification of the devices, including manufacturee's data and device's origin, evaluation of manometer calibration; and evaluation of the physical conditions of the cuff, bulbs and and valves.

To evaluate the calibration, the aneroid manometer was tested against a mercury manometer, using a Y-shaped connector according to the following procedure: to connect the aneroid manometer to be tested, the mercury manometer and the rubber pump to the three ends of the Y-shaped connector; then inflate the system until it exceeds $250 \mathrm{~mm}$ $\mathrm{Hg}$, open the rubber pump valve slowly to reduce pressure, check the correspondence of values between the two manometers at the levels of 250, 200, 150, 100, 50 and $0 \mathrm{~mm} \mathrm{Hg}$, and identify the magnitude of error in $\mathrm{mm} \mathrm{Hg}$ in the correspondence of values at each level. The aneroid manometers were considered accurately calibrated when the error was $\leq 3 \mathrm{~mm} \mathrm{Hg}$, what corresponds to $1 \%$ of the total scale ${ }^{6}$. Evaluation of the physical conditions of the device was carried out. The cuff - rubber bladder and bulbs, pump and valve - were all examined for rubber aging, leaks, and holes.

\section{Results}

The first feature to be evaluated was the calibration of the aneroid sphygmomanometers tested. The data in Figure 1 show that $51 \%$ of aneroid devices used in private practice by Brazilian doctors and $56 \%$ of those used in the two public hospitals in the city of São Paulo were uncalibrated. For $70 \%$ and $51 \%$ of the private practice and hospitals manometers, respectively, the magnitude of error in the uncalibrated devices ranged from 4-8mm $\mathrm{Hg}$ (fig. 2). Most of the differences $(76 \%)$ observed were towards lower values. However, it was at the highest level of the test $(250 \mathrm{~mm} \mathrm{Hg})$ that the differences were statistically significant ( $p<0.05)$, (fig. 3).

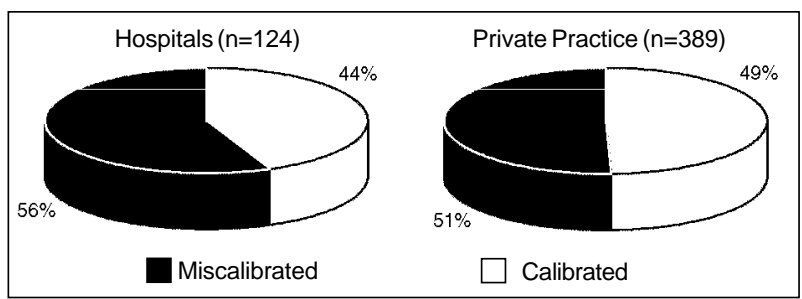

Fig. 1 - Calibration of aneroid sphygmomanometers used in hospitals and private practice.

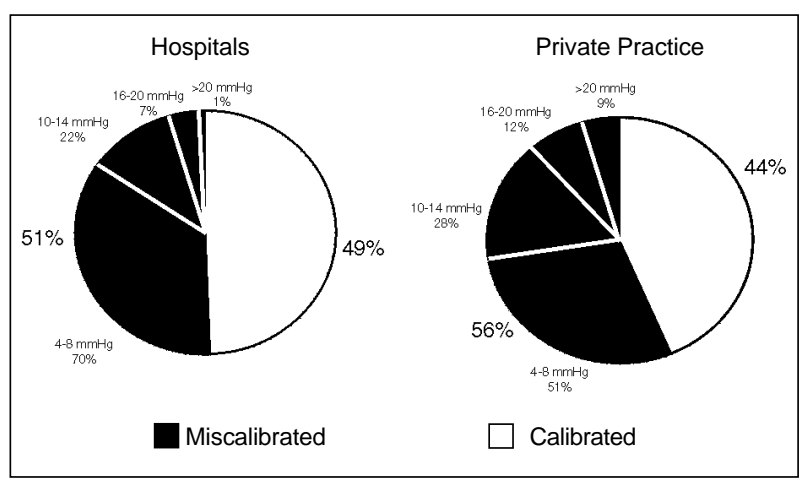

Fig. 2 - Calibration and magnitude of miscalibration of the devices. 


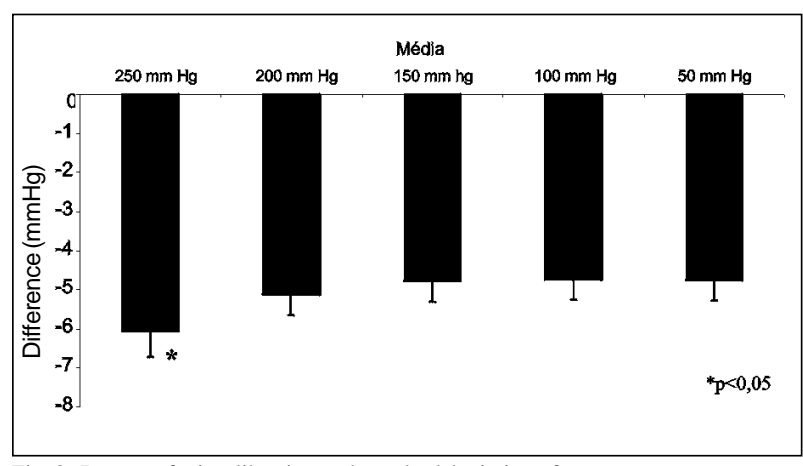

Fig. 3 - Degree of miscalibration and standard deviation of manometers.

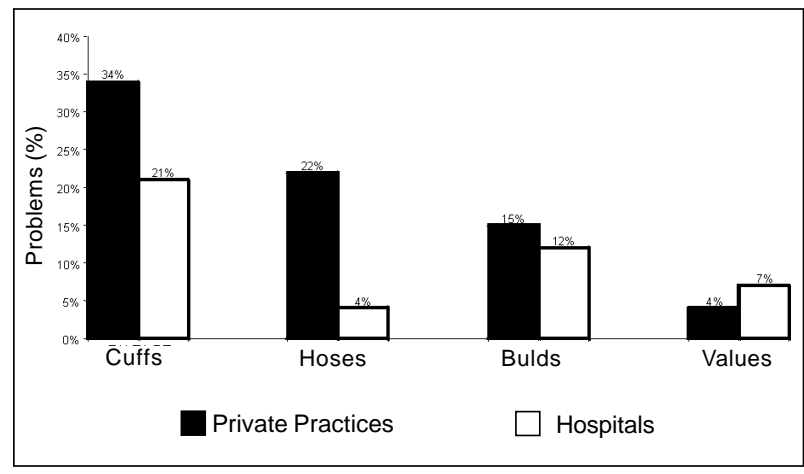

Fig. 4 - Problems with cuffs, hoses, bulb pumps and valves of equipment evaluated

The second evaluated feature was the physical conditions of the rubber bladder, bulbs, pump, and valve. The data in Figure 4 show the problems found in the cuff rubber bladder and bulb, pump, and valve of private and hospital devices. The most frequent defects were bladder damage (34\% / 21\%), holes/leaks in the bulbs $(22 \% / 4 \%)$, and rubber aging aging (15\% / 12\%), respectively. Most of the sphygmomanometers evaluated $(72 \%)$ revealed at least one problem related either to calibration or the physical conditions of the cuff - rubber bladder, bulb pump, and valve that interfere with blood pressure measurement accuracy.

\section{Discussion}

The main result of the present study is that approximately $50 \%$ of the aneroid devices used to measure blood pressure were uncalibrated, which could lead to errors in blood pressure measurement. Moreover, $70 \%$ of the sphygmomanometers evaluated revealed at least one problem related either to calibration or to the physical conditions of the cuff - bladder, bulb, pump, and valve, what is very important as it can also cause blood pressure measurement error.

The fact that the needle of an aneroid manometer coincides with the zero level on the scale does not mean that the device is properly calibrated. As this fact is not generally known by most health-care professionals, it may explain the high percentage of uncalibrated aneroid manometers. Moreover, the unawareness that checking for aneroid
Sphygmomanometer accuracy and their physical conditions

devices calibration is not a simple, since it requires testing the aneroid manometer against a mercury one by using a Y shaped connector can be an additional factor to this rate of uncalibration.

Inaccurate calibration is easily identified in mercury manometers since it is considered calibrated when the meniscus does not coincide with zero, however, they are not easy by transported.

Few studies have analyzed the percentage of calibration error in equipment for measuring arterial blood pressure. Bailey et $\mathrm{al}^{6}$ tested 230 aneroid manometers and found that $35 \%$ were not adequately calibrated; Burke et al ${ }^{7}$ also conducted a study to evaluate the conditions of manometers and found that $30 \%$ of the aneroid devices had a magnitude of error $>4 \mathrm{~mm} \mathrm{Hg}$ vs. only $2 \%$ of the mercury devices. In Brazil, a study that also evaluated calibration conditions of blood pressure measuring devices reported that $58 \%$ of the aneroid manometers and $21 \%$ of the mercury manometers were not well calibrated ${ }^{8}$. It is of course possible that much of the lack of calibration found in the present study may have been due to the methodology used. As the doctors were invited to bring their equipment for evaluation, it is possible that they intentionally brought the ones they suspected to be uncalibrated. Regarding private practice and hospital manometers, we expected hospital devices to have a much higher percentage of inaccurate calibration, however, it was only slightly higher than that of private practice manometers ( $51 \%$ vs. $56 \%$ ). Despite the fact that all 124 sphygmomanometers tested were obtained from only two teaching hospitals, the results suggest unsatisfactory conditions of the equipment. Regarding the source of the manometers, Gomes et al ${ }^{9}$ observed that the aneroid manometers used in outpatient clinics had errors ranging from 2 to $2.8 \mathrm{~mm} \mathrm{Hg}$ whereas those found in hospital first-care areas had a range of error of 5.5 to $6.8 \mathrm{~mm} \mathrm{Hg}$. When the specific origin of the equipment was considered, $69 \%$ of the sphygmomanometers were evaluated in the southeast and the others in the northeast. The fact that most of the sphygmomanometers evaluated in this study presumably come from the city of Rio de Janeiro and the state of São Paulo, is remarkable since these are places where the best healthcare services of Brazil are located.

Another finding that draws attention in the present study is the magnitude of inaccurate calibration. Nearly $30 \%$ of the devices used in private practice and $50 \%$ of those used in hospitals were not accurately calibrated, with magnitude of error $>10 \mathrm{mmHg}$. These data are similar to those obtained by McKay et al ${ }^{10}$, who found $40 \%$ of the aneroid sphygmomanometer in outpatient clinics to be inadequately calibrated, considering that $30 \%$ of them had a magnitude of error $>10 \mathrm{~mm} \mathrm{Hg}$. Jones et al. ${ }^{11}$ also found $34 \%$ of the aneroid devices to be out of calibration, and of those, $10 \%$ had errors higher than $8 \mathrm{~mm} \mathrm{Hg}$. Likewise, in the study carried out by Baley et al., $35 \%$ of the manometers evaluated deviated by more than $3 \mathrm{~mm} \mathrm{Hg}$.

It should be emphasized that most of the deviations found $(76 \%)$ were in the downward direction. This blood 
pressure underestimation implies a false normotension for people with blood pressure readings higher than the one considered normal. This failure to diagnose hypertension is thus depriving them of the benefits of treatment and may contribute to greater damage to target organs.

Another aspect that must be emphasized is that the grater magnitudes of error were found at the highest level $(250 \mathrm{~mm} \mathrm{Hg})$. Other studies also showed that the errors occur distinctly at the different levels of the evaluation. Fisher observed differences exceeding $3 \mathrm{~mm} \mathrm{Hg}$ in $22 \%$ of the devices at $60 \mathrm{~mm} \mathrm{Hg}$, in $25 \%$ at $120 \mathrm{~mm} \mathrm{Hg}$, in $29 \%$ at $180 \mathrm{~mm}$ $\mathrm{Hg}$, and in $34 \%$ at $240 \mathrm{~mm} \mathrm{Hg}^{12}$. Cady et al ${ }^{13}$ analyzed 150 sphygmomanometers in an emergency unit and found that $28 \%$ of them were not adequately calibrated at $90 \mathrm{~mm} \mathrm{Hg}$.

Not only the manometers, but also the physical conditions of the cuff - rubber, bulb, pump, and valve must also be evaluated. Rubber bladder damage due to holes/ leaks and rubber aging observed in approximately a third of the devices can easily lead to errors in measurement, and suggests lack of maintenance of the equipment, whereas better maintenance could provide adequate conditions of use. The presence of holes in the bulbs and leaks in the valves jeopardize the inflation and deflation system. Leaks in the control valves make inflation of the rubber bladder difficult, and the speed of deflation difficult to control. This can cause erroneous readings with underestimation of the systolic pressure and overestimation of the diastolic pressure. Similar problems, associated with aging were also observed for rubber bulbs and pumps in the evaluation of the devices. Replacement or cleaning of the valve of the inflation-deflation system and the exhaust valve of the rubber pump, however, should eliminate these problems.

Thus, numerous possibilities for error due to the lack of maintenance of such equipment were found and point to the importance of a periodic evaluation. Surprisingly, several guides concerned with blood pressure measurement have been published, aiming at unifying the procedure and warn health-care practitioners about potential errors that can jeopardize the results obtained. Yet these books fail to stress the importance of checking regularly the calibration of the equipment used ${ }^{1-5}$. In the medical area, the National Institute of Metrology has established guidelines for equipments used to measure blood pressure so that only equipment with the seal of this organization should be authorized for use. Considering all of the problems identified in the present study, whether in relation to the calibration of the manometer or the physical conditions of the rubber bladders, hoses, bulbs and pumps, it was observed high incidense of inaccurate devices, since $72 \%$ out of the total sample had problems that jeopardize blood pressure measurement accuracy.

Although the ideal interval for maintenance checkups has to be determined, yet a checkup of the calibration of the sphygmomanometer should by carried out every six months to reduce the high incidence of problems in these devices.

Therefore, blood pressure measurement using the manometer and auscultatory method is a simple and easily executed procedure that provides reliable results, as long as certain basic premises are respected, among these the adequate physical conditions of the devices involved. Decisions in relation to the diagnosis of hypertension and what therapeutic treatment should be adopted are based on the results of blood pressure measurement. Given the results of this study, it is extremely important that institutions involved with health-care carry out campaigns to furnish health-care professionals with information and update them about this issue, emphasizing how important a six-month check-up of the devices is to guarantee blood pressure measurement accuracy.

\section{References}

1. National Institute of Health, National Heart, Lung, and Blood Institute. The Sixth Report of the Joint Nacional Committee on Prevention, Detection,Evaluation, and Treatment of High Blood pressure, 1997; 153p: 154-83.

2. Sociedade Brasileira de Hipertensão, Sociedade Brasileira de Cardiologia, Sociedade Brasileira de Nefrologia. III Consenso Brasileiro de Hipertensão Arterial, 1998: 1-5.

3. Zanchetti A, Chalmers JP, Arakawa K, et al. The 1993 Guideliness for the management of mild hypertension: memorandun from WHO/ISH meeting. Hypertension 1993; 22: 392-403.

4. Perloff D, Grim C, Flack J, et al. Human blood pressure determination by sphygmomanometry. Circulation 1993; 88: 2460-70.

5. Frohlich E, Grim C, Labarthe DR, et al. Recomendations for human blood pressure determination by sphigmomanometers. Circulation 1988; 77: 5O1A-514.

6. Bailey RH, Knaus VL, Bauer JH. Aneroid Sphygmomanometers. Arch Intern Med 1991; 15 I: 1409-12.
7. Burke Mj, Towers HM, O'Malley K, Fitzgerald DJ, O'Brien ET. Sphygmomanometers in hospital and family practice: problems and recomendations. Br Med J 1982; 285: 469-71.

8. Mion Jr D, Pierin AMG. How accurate are sphygmomanometers? J Hum Hypertens 1998; $12: 245-8$.

9. Gomes V, Bedirian R, Araújo PH, Oigman W. Uso freqüente de manômetros do tipo aneróide, um erro a mais na leitura da pressão arterial. Arq Bras Cardiol 1995; 65(supl. I): 8.

10. McKayDW,etal.Clinical Assessmentofbloodpressure.JHumHypertens 1990;4:639-45.

11. Jones JS, Ramsey W, Hetrick T. Accuracy of prehospital sphygmomanometers. J Emer Med 1987: 5: 23-7.

12. Fisher HW. The aneroid sphygmomanometer: an assessment of accuracy. Med Cardiovasc 1978; 3: 769-71.

13. Cady CE, Pirrallo RG, Grim CE. Ambulance sphygmomanometers are frequently inaccurate. Am J Hypertens 1996; 9: 107A. 